\title{
Effect of Multiple Weld Thermal Cycles on HSLA-100 Steel
}

\author{
The microstructure and mechanical properties of high-strength low-alloy \\ steel during multipass welding was analyzed
}

BY J. E. DUCH AND J. N. DUPONT

\begin{abstract}
High-strength low-alloy (HSLA)-100 is a precipitatestrengthened low-alloy steel that is often used for its good combination of high yield strength and impact toughness. During initial fabrication and service, multipass welds and weld repairs often need to be made. Work has been done to determine the properties in the heat-affected zone (HAZ) for HSLA-100, but fewer results are available to understand microstructural evolution and the resultant properties of the HAZ under multipass welding conditions. Variations in the HAZ hardness were observed and shown to be associated with compositional banding. These differences between the enriched and depleted solute bands led to differences in hardenability. Thermodynamic and diffusion simulations demonstrated that carbon preferentially segregates to the regions of higher concentration of substitutional elements, thus increasing the hardness. This difference in composition also led to changes in the transformation temperatures and caused local differences in the HAZ microstructure. Multiple-pass autogenous welds confirmed that this compositional banding has a greater effect on hardness than multiple weld thermal cycles. HAZ simulations showed the hardness in all regions of the HAZ was higher than that of the base metal (BM). The impact toughness of the HAZ was equal to or higher than the BM, except for the coarse-grain HAZ (CGHAZ), which was slightly below the acceptable minimum for the BM. However, the CGHAZ toughness did not degrade further after three weld thermal cycles. The reheated CGHAZ showed a rejuvenation in toughness for subsequent thermal cycles with peak temperatures of $810^{\circ}$ and $900^{\circ} \mathrm{C}$. The phase transformations in the intercritical HAZ (ICHAZ) region were still unfinished after three weld thermal cycles, and the progressive transformation with each successive pass increased the hardness and decreased the toughness. However, fully transformed ICHAZ samples still maintained excellent impact toughness and high hardness. Additional samples underwent weld simulations after a $10 \%$ prestrain to study how plastic strain from residual stress and service would influence the resulting properties. Except for the CGHAZ, all regions of the strained BM and HAZ still exhibited toughness values above the minimum requirements.
\end{abstract}

\section{KEYWORDS}

- HSLA-100 • High-Strength Steels • Martensitic Steels - Ferritic Steels • Mechanical Properties • GTAW • HAZ

- Impact Toughness • Hardness Maps • HAZ Simulations

- Thermodynamic Simulations • EPMA

\section{Introduction}

Modern high-strength low-alloy (HSLA) structural steels are used in the construction of buildings, bridges, pipelines, and ships requiring high strength and toughness along with good weldability. HSLA-100 obtains high strength through fine precipitates (niobium carbonitrides and copper), high toughness through microstructural features like fine acicular ferrite, and good resistance to hydrogen cracking by having low carbon levels (less than about $0.08 \mathrm{wt}-\%$ ). The microstructure and properties of the heat-affected zone (HAZ) of HSLA-100 and other HSLA steels have been explored (Refs. 1-6). During the heating stage of the weld thermal cycle, the HAZ may transform the matrix phase into austenite and coarsen or dissolve strengthening precipitates. The austenite will then retransform to martensite, bainite, or ferrite, depending on the cooling rate.

Many welding processes used for fabrication and repair of HSLA steels require multiple weld passes associated with relatively large section thicknesses. In this case, the HAZ undergoes a wide range of peak temperatures during each successive weld thermal cycle. The "starting microstructure" will no longer be that of the unaffected base metal, but can be a preHAZ region that subsequently experiences a completely new set of thermal conditions. Weld repairs will expose a section of the HAZ to many successive thermal cycles within the same region. The potential effect of these multiple thermal cycles and cumulative plastic strain from residual stress, which can accelerate precipitation kinetics (Refs. 7-12), has yet to be addressed in HSLA-100. Thus, it is currently unknown if an upper limit exists to the number of weld repairs that can be made while maintaining adequate properties for the intended service. Studies on other low-alloy steels have shown the presence of a local brittle zone (LBZ) in reheated sections of the HAZ, 

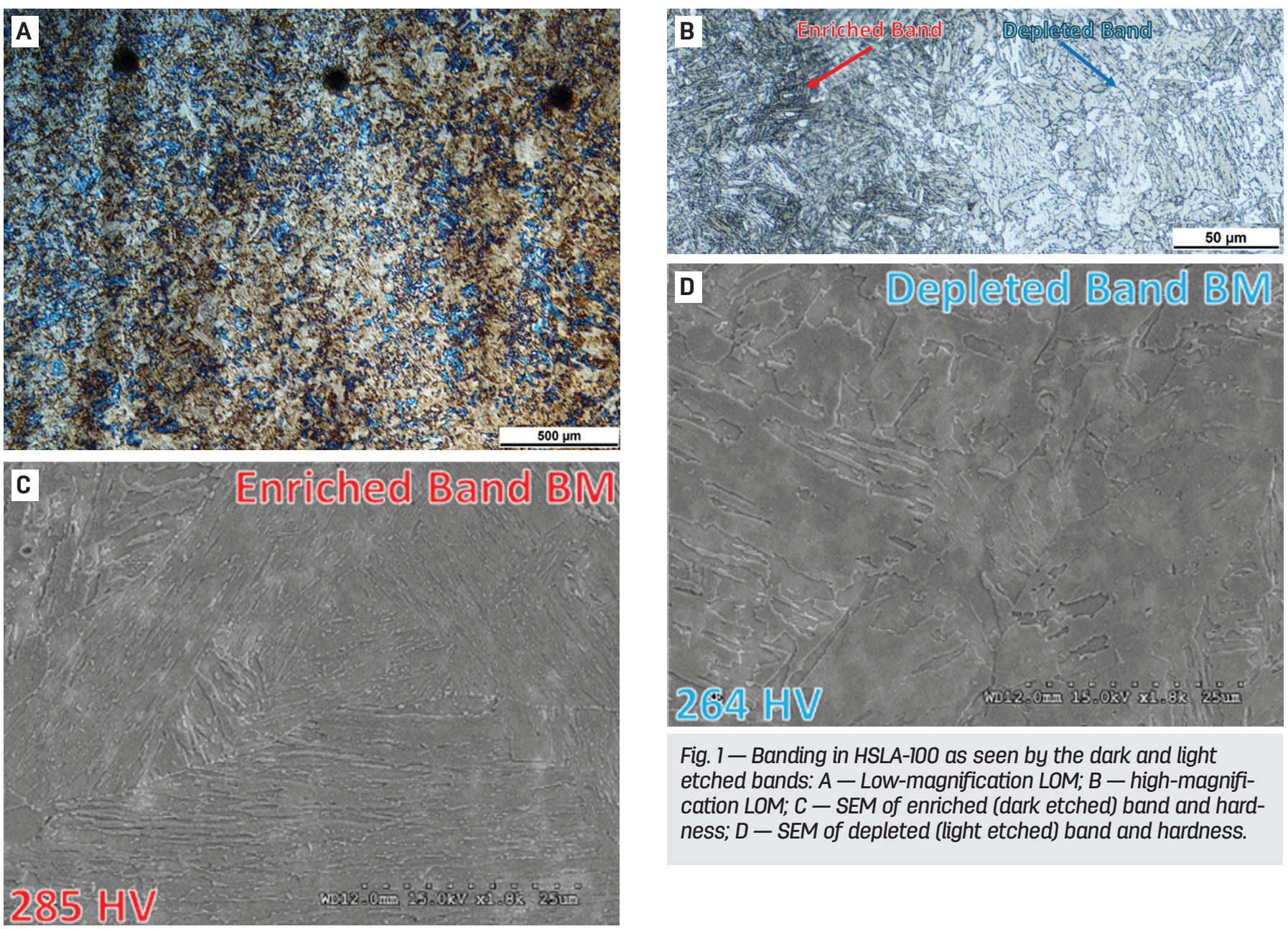

Fig. 1- Banding in HSLA-100 as seen by the dark and light etched bands: A - Low-magnification LOM; B - high-magnification LOM; C - SEM of enriched (dark etched) band and hardness; $D$ - SEM of depleted (light etched) band and hardness.

Table 1 - Alloy Composition (in wt-\%) of the HSLA-100 Steel Employed in This Study

\begin{tabular}{ccccccccccccccc}
$\mathrm{C}$ & $\mathrm{Mn}$ & $\mathrm{P}$ & $\mathrm{S}$ & $\mathrm{Si}$ & $\mathrm{Cu}$ & $\mathrm{Ni}$ & $\mathrm{Cr}$ & $\mathrm{Mo}$ & $\mathrm{Al}$ & $\mathrm{Nb}$ & $\mathrm{V}$ & $\mathrm{Fe}$ \\
\hline 0.08 & 0.85 & 0.01 & 0.002 & 0.24 & 1.53 & 3.58 & 0.58 & 0.61 & 0.027 & 0.025 & 0.002 & Bal.
\end{tabular}

which may locally decrease the toughness of that region (Refs. 13-20). Considering that HSLA steels rely on a complex heat treatment, copper precipitation strengthening, and tempered low-carbon martensite to achieve the desired strength and toughness, it is essential to develop a fundamental understanding of how the HAZ strength and toughness change with different thermal cycle combinations.

This study analyzes the hardness of multipass autogenous welds along with the hardness and toughness of simulated HAZ samples in HSLA-100. The results of this work provide insight into the microstructural evolution and concomitant mechanical properties during multipass welding of this steel, and demonstrate that multiple weld thermal cycles do not have a significantly detrimental effect on mechanical properties.

\section{Experimental Procedure}

HSLA-100 material was obtained with procurement specification ENG-TS-JEI-0083(U), Rev. B. The chemical composi- tion of the HSLA-100 was determined by using the spark optical emission spectroscopy (spark-OES) method, shown in Table 1. A 3-in.-thick section of the steel was formed at $1165^{\circ} \mathrm{C}$ for $180 \mathrm{~min}$ and air cooled, followed by two separate austenization treatments at $930^{\circ}$ and $891^{\circ} \mathrm{C}$ for $228 \mathrm{~min}$ each with a water quench after each treatment. The alloy was quenched and then aged at $602^{\circ} \mathrm{C}$ for $200 \mathrm{~min}$ followed by an additional age at $630^{\circ} \mathrm{C}$ for $240 \mathrm{~min}$ and then water quenched to achieve the desired mechanical properties.

Autogenous gas tungsten arc welding (GTAW) passes were made on HSLA-100 weld plates at heat inputs of 980 and $1730 \mathrm{~J} / \mathrm{mm}$, which covered the typical range for the application of interest. Multipass weld samples, where an autogenous weld pass was made directly on top of the previous weld pass, were prepared for each heat input. This process was repeated up to ten passes. Vickers microhardness maps with a 100-g load and dwell time of $5 \mathrm{~s}$ were performed on sections of the weld that included the base metal, HAZ, and fusion zone for each weld pass at each heat input.

Thermal cycles that were used for the HAZ simulations 
were calculated by Sandia's SmartWeld (SOAR) program under three-dimensional heat flow conditions (typical for thick plates) using a heat input of $1730 \mathrm{~J} / \mathrm{mm}$ (Refs. 21-23). A Gleeble ${ }^{\circledR} 3500$ thermomechanical simulator was used to perform the $\mathrm{HAZ}$ simulations. Five peak temperatures of $675^{\circ}, 750^{\circ}$, $810^{\circ}, 900^{\circ}$, and $1300^{\circ} \mathrm{C}$ were used to represent the subcritical HAZ (SCHAZ), intercritical HAZ (ICHAZ), high-intercritical HAZ (HICHAZ), fine-grain HAZ (FGHAZ), and coarse-grain HAZ (CGHAZ), respectively. Multipass samples are described by the thermocycle reheat condition followed by the first-pass thermocycle. For example, the intercritically reheated coarse grain heat-affected zone would be written ICR CGHAZ. The two intercritical temperatures were chosen to be at the low temperature $\left(750^{\circ} \mathrm{C}\right)$ and high temperature $\left(810^{\circ} \mathrm{C}\right)$ of the intercritical region. Single-pass HAZ samples were made as well as multipass samples, which exposed a sample to back-to-back identical thermal cycles. The CGHAZ samples that were exposed to a single thermal cycle were also exposed to subsequent thermal cycles with different peak temperatures.

The influence of a pre-strain on the HAZ properties was also considered. This was done to investigate the influence of strain that can occur in the HAZ due to residual stress along with plastic deformation that may occur in service between weld repairs. For this part of the study, a bar of HSLA-100 with dimensions $30 \times 40 \times 155 \mathrm{~mm}$ was compressed to $10 \%$ strain before the HAZ simulations. The $10 \%$ plastic strain level was based on the upper limit to plastic strain that would be expected based on known service conditions. The samples used for all the HAZ simulations were $11 \times 11 \times 70 \mathrm{~mm}$ rectangular bars. Charpy testing was performed at $-84^{\circ} \mathrm{C}$ on standard size samples machined down from the HAZ bars. The HAZ samples were also analyzed via microhardness and microscopy.

Samples for microstructural characterization were prepared using standard metallographic techniques with a 0.05$\mu \mathrm{m}$ colloidal silica final polish. Samples were etched in $2 \%$ Nital. Microstructural characterization was performed on a Reichert-Jung MeF3 inverted light optical microscope (LOM). Higher magnification scanning electron microscopy (SEM) was performed using a Hitachi 4300 FEG/SEM with a $15-\mathrm{kV}$ acceleration voltage. Local chemical information from electron probe microanalysis (EPMA) measurements employing wavelength-dispersive spectrometry (WDS) was performed using a JEOL JXA-8900 microprobe with a step size of $4.5 \mu \mathrm{m}$. Thermodynamic and diffusion simulations were carried out with Thermo-Calc and DICTRA software (Refs. 24-28) using TCFE8 and MOBFE4 databases.

\section{Results and Discussion}

Dilatometry data for HSLA-100 was collected, and it was found that at $300^{\circ} \mathrm{C} / \mathrm{s}$ (a typical heating rate for welding) the $\mathrm{Ac}_{1}$ temperature was $740^{\circ} \mathrm{C}$ and the $\mathrm{Ac}_{3}$ temperature was $840^{\circ} \mathrm{C}$. The $\mathrm{Ac}_{1}$ temperature was higher than literature values of $600^{\circ} \mathrm{C}$ (Ref. 1), but those literature values are for slow heating rates.

\section{Remnant Segregation in the Base Metal}

As discussed in more detail later in this paper, microstructural evolution in the HAZ during multiple thermal

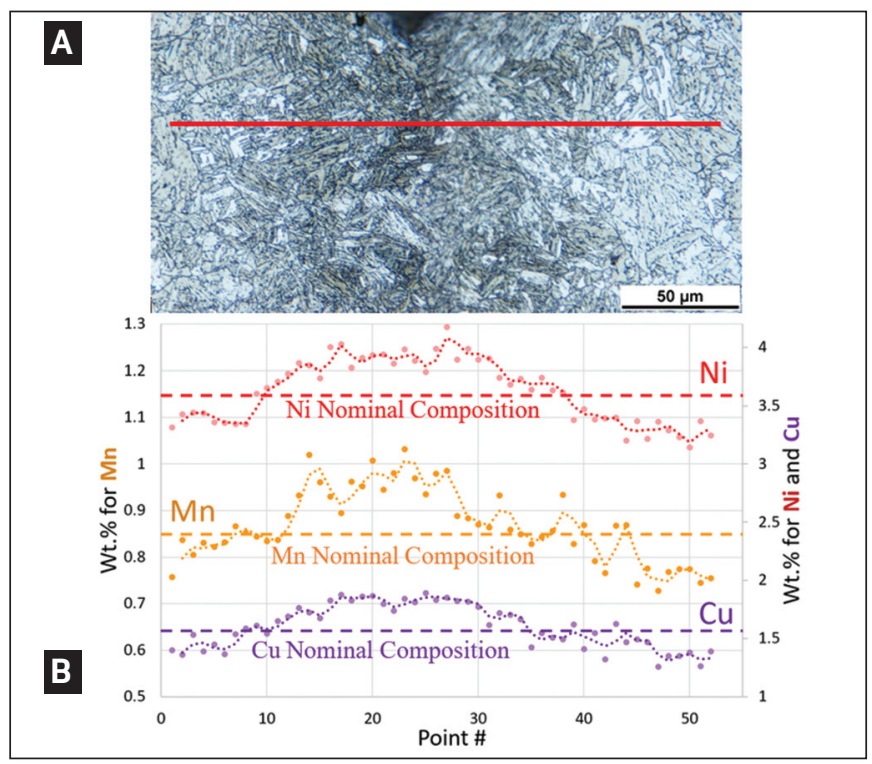

Fig. 2 - A - LOM of base metal; B - with WDS semiquantitative chemical composition.

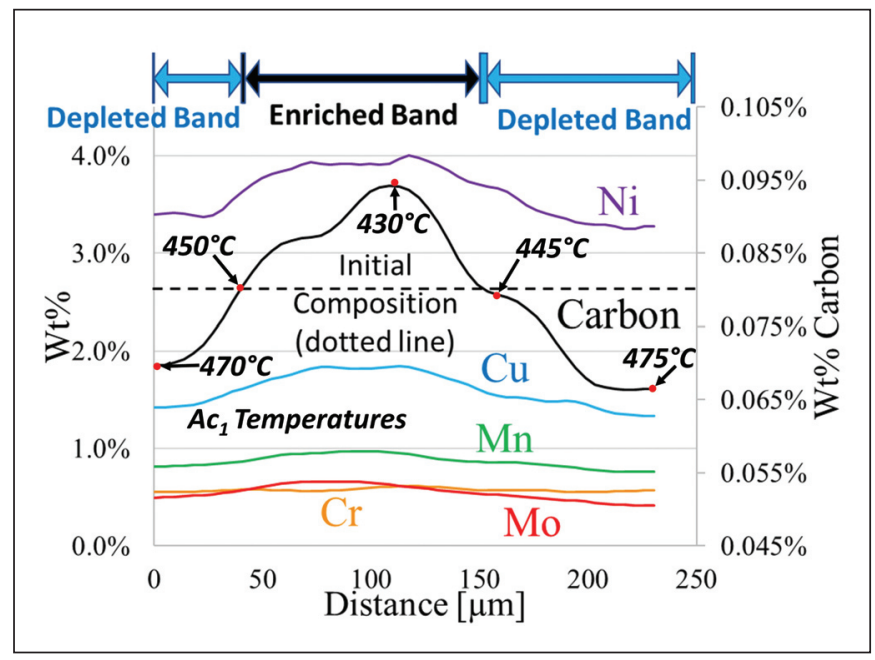

Fig. 3 - DICTRA diffusion simulation after typical heat treatment to determine carbon segregation. Simulated $A c_{1}$ temperatures are labeled along the carbon composition line.

cycles was found to be controlled, in large part, by remnant segregation in the base metal and associated variations in microstructure. The remnant segregation persists from segregation during solidification of the original ingot that was not fully homogenized by subsequent thermal treatments, or from thermal fluctuations from the initial casting, and is commonly observed in HSLA and other steels (Refs. 1, 29, 30). An example of this microstructural banding is shown by the LOM images, with SEM micrographs and hardness values in Fig. 1.

The remnant segregation and associated variation in microstructure is shown by the regions in Fig. 1A that, when etched, appear light and dark within the base metal. Higher magnification images of the bands are shown in the LOM images in Fig. 1B. SEM images of each region are provided in Fig. $1 C$ and D, which show a finer structure of lath marten- 


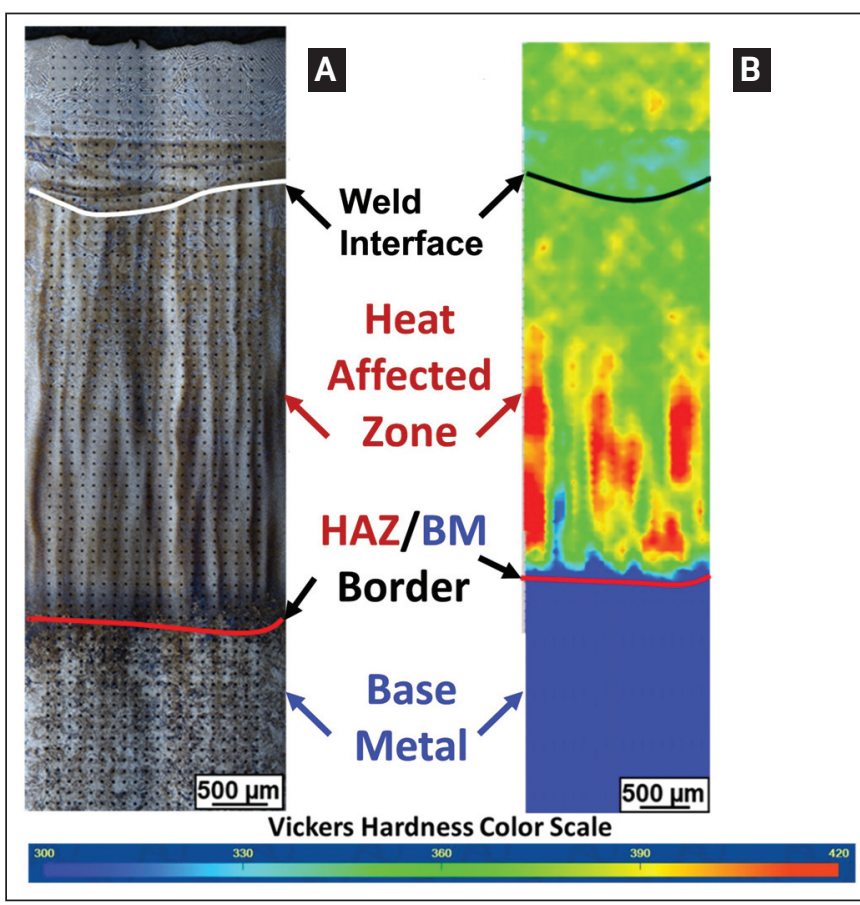

Fig. 4-A - LOM of indented multipass weld at $1730 \mathrm{~J} / \mathrm{mm}$ heat input; $B$ - with hardness map with Vickers color scale.

site in the enriched band than in the depleted band. Note that these local variations in microstructure produce variations in hardness of the BM between 264 and 285 HV.

EPMA results acquired across a banded region (Fig. 2) demonstrate that $\mathrm{Ni}, \mathrm{Mn}$, and $\mathrm{Cu}$ are enriched in the darkly etching band and depleted in the lightly etching band. These gradients in substitutional elements will produce a carbon chemical potential gradient that will, in turn, produce local variations in the carbon concentration.

A diffusion simulation using DICTRA (Fig. 3) was performed in which the measured solute profiles of the substitutional elements, nominal carbon concentration, and known thermal history of the base metal (described earlier in the Experimental Procedure section) were used as inputs to the model calculations. The carbon was enriched to $\sim 0.094 \mathrm{wt}-\%$ in the enriched regions and depleted to $\sim 0.066 \mathrm{wt}-\%$ in the depleted regions. The observed difference in hardness within these regions can be attributed to the higher concentrations of both substitutional elements and carbon that will locally increase the hardness due to solid solution strengthening. The locally increased carbon concentration is particularly important, since carbon is the most significant martensite strengthener (Refs. 31, 32). Thus, this banding difference will be more exaggerated
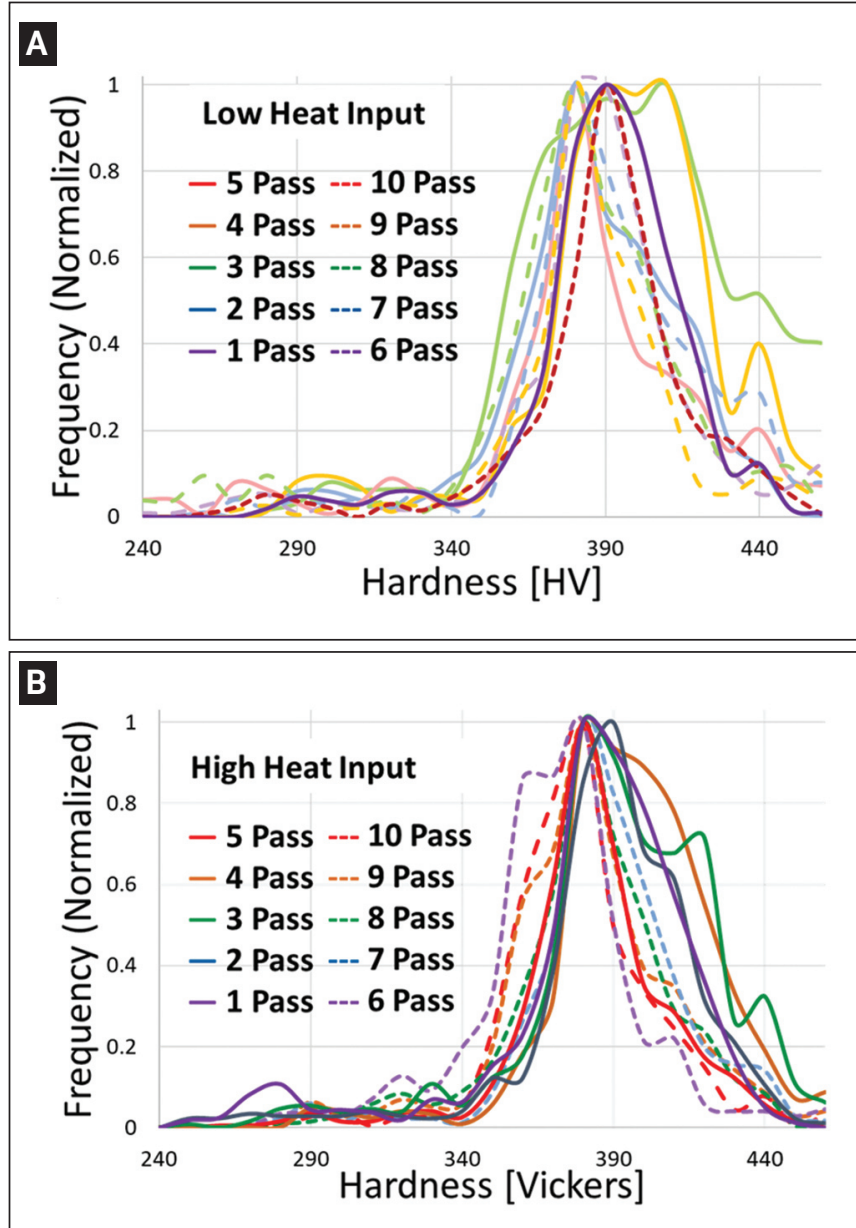

Fig. 5- Histogram of hardness in the HAZ for each weld pass. A - Low-heat input; B - high-heat input.

when fresh martensite is present, which often occurs in the $\mathrm{HAZ}$ when the peak temperature is above $A c_{1}$.

The composition of each band from the EPMA data and DICTRA diffusion simulations as well as their calculated transformation temperatures (from Thermo-Calc) are shown in Table 2. These simulations estimate an $\mathrm{Ac}_{1}$ and $\mathrm{Ac}_{3}$ temperature of $460^{\circ}$ and $760^{\circ} \mathrm{C}$, respectively, for the nominal composition. The depleted band had calculated $\mathrm{Ac}_{1}$ and $\mathrm{Ac}_{3}$ temperatures of $480^{\circ}$ and $770^{\circ} \mathrm{C}$, respectively, while the enriched band had calculated $A c_{1}$ and $A c_{3}$ temperatures of $420^{\circ}$ and $750^{\circ} \mathrm{C}$. The lower $A c_{1}$ temperature for the enriched band means that, for a given HAZ intercritical temperature, there is a greater driving force for austenite growth than for the depleted band. The actual $A c_{1}$ and $A c_{3}$ temperatures as determined by dilatometry (which provide average transformation tempera-

Table 2 - Thermo-Calc Simulation Results for Slight Changes in Composition from Banding

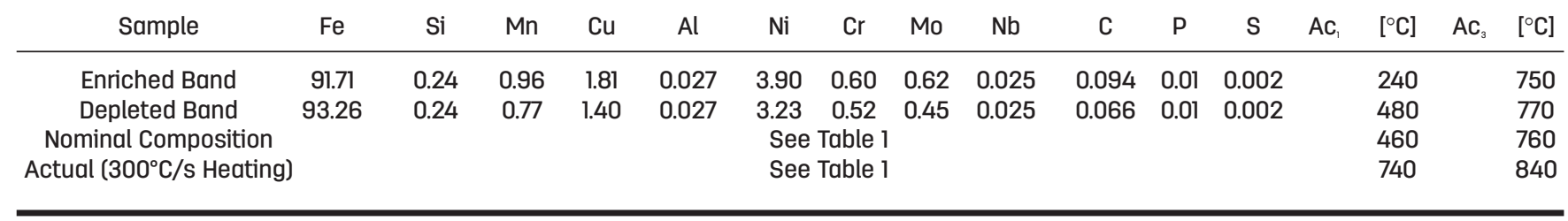




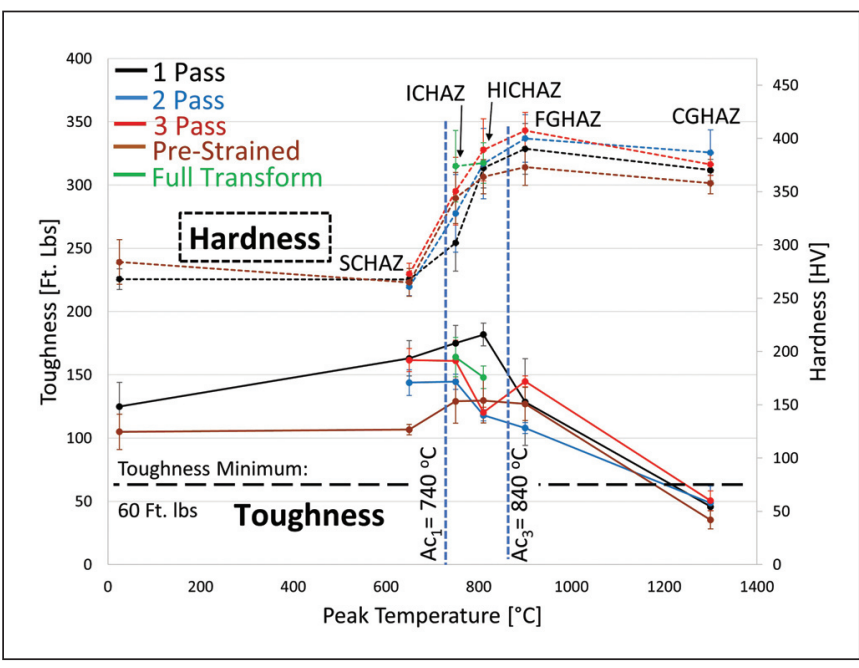

Fig. 6 - Hardness and impact toughness for single-pass and multipass simulated HAZ samples.

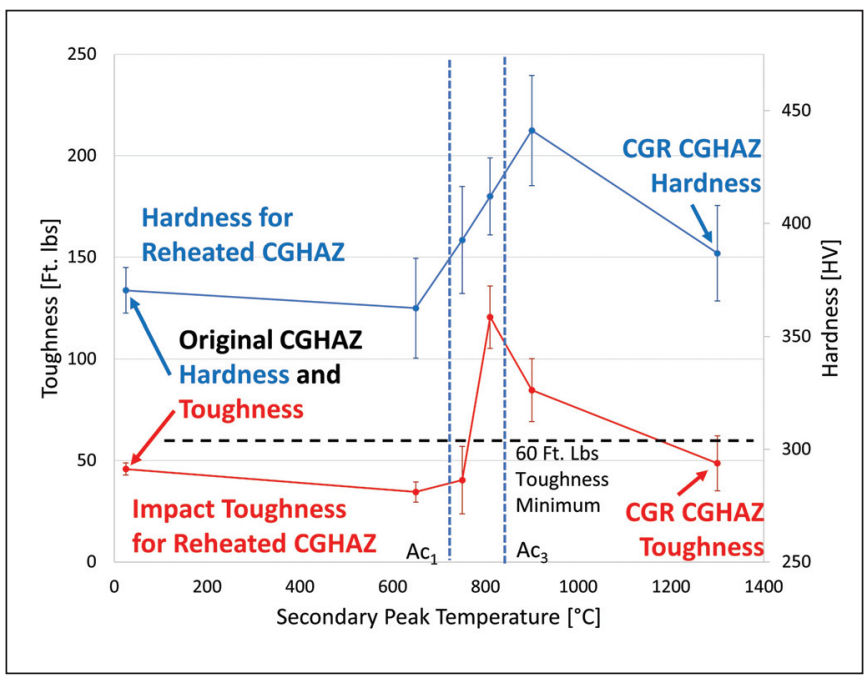

Fig. 8- Hardness and toughness for reheated CGHAZ samples.

tures) are much higher, $740^{\circ}$ and $840^{\circ} \mathrm{C}$, respectively.

However, the trends should be consistent. The enriched band will have lower $\mathrm{Ac}_{1}$ and $\mathrm{Ac}_{3}$ temperatures than the nominal composition, while the depleted region will have higher transformation temperatures. This difference in transformation temperatures will lead to microstructural differences between the bands in the HAZ, especially in the intercritical region. The enriched band, with a lower $\mathrm{Ac}_{1}$, will more rapidly nucleate and grow austenite than the depleted band. The higher solute composition in this region can also affect stability of the resultant transformation products due to local changes in the hardenability.

\section{Autogenous Welds}

Figure 4 shows a typical example of hardness variations in the HAZ after successive passes were applied with autogenous GTA welds. The hardness variations due to banding in the $\mathrm{BM}$ ranged from 259 to 277 (19 HV difference). In the $\mathrm{HAZ}$, in comparison, the largest hardness variance was from

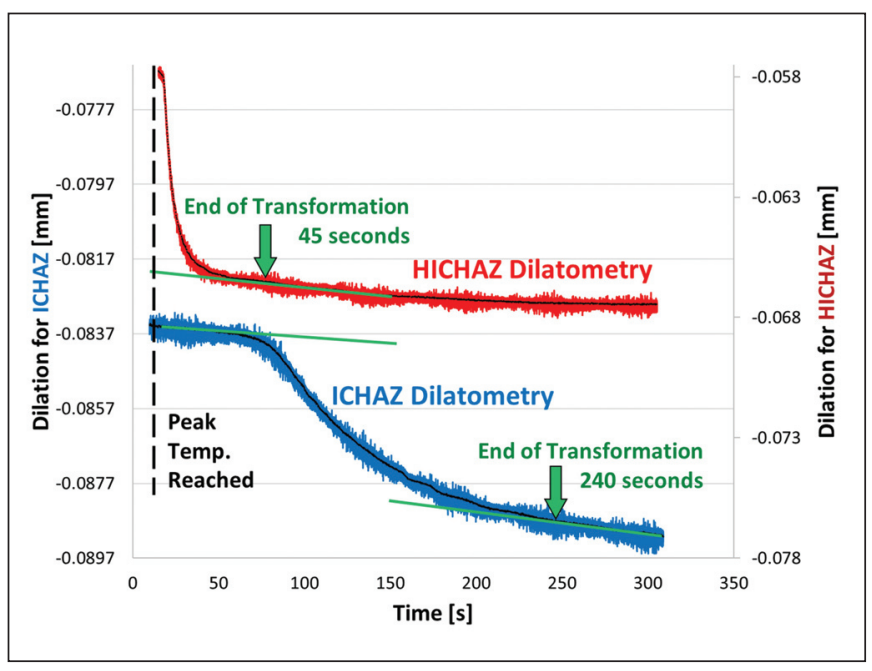

Fig. 7 - Dilation plot of ICHAZ and HICHAZ with the transformation start and finish labeled.

360 to $440 \mathrm{HV}$ (80 HV difference). The enriched bands (shown by the red areas on the hardness map) and depleted bands (shown by the light green areas on the hardness map) in the HAZ have corresponding higher and lower hardness, respectively.

Figure 5 provides a summary of all the hardness maps in the form of a histogram for each heat input considered. The maximum hardness in the hardness histograms, $440 \mathrm{HV}$, is typical of the enriched region. The depleted region hardness is typically $360 \mathrm{HV}$. The most frequent hardness value, around $390 \mathrm{HV}$, is in fact the transition region between the enriched and depleted band. If there was a hardening or softening trend with subsequent weld passes, the most frequent hardness, which is the peak of the graph, would shift left or right to indicate a trend toward an increase or decrease in hardness.

However, the histogram does not show any systematic differences in hardness frequency values when all ten weld passes are considered. Any possible trend in HAZ hardness with successive weld passes appears to be masked in the histogram by the relatively large variations in hardness between the solute enriched and depleted regions (that is clearly evident in the hardness map shown in Fig. 4). Some small peaks do emerge, especially for the low-heat-input samples, but this is most likely due to the banding effect as well. The number of indents in the HAZ for the low heat input (525) was smaller than for the high heat input (805) simply due to the smaller HAZ size for the low heat input. Therefore, it was more sensitive statistically to oversampling from the enriched or depleted band. Thus, the effect of banding on the HAZ hardness is more significant than any possible change in hardness from multiple weld thermal cycles.

\section{Simulated HAZ Gleeble Samples}

The hardness and impact toughness for each section of the HAZ for single, multipass (two and three pass), "fully transformed," and prestrained samples are summarized in Fig. 6 (the "fully transformed" samples are further discussed later in this paper). 

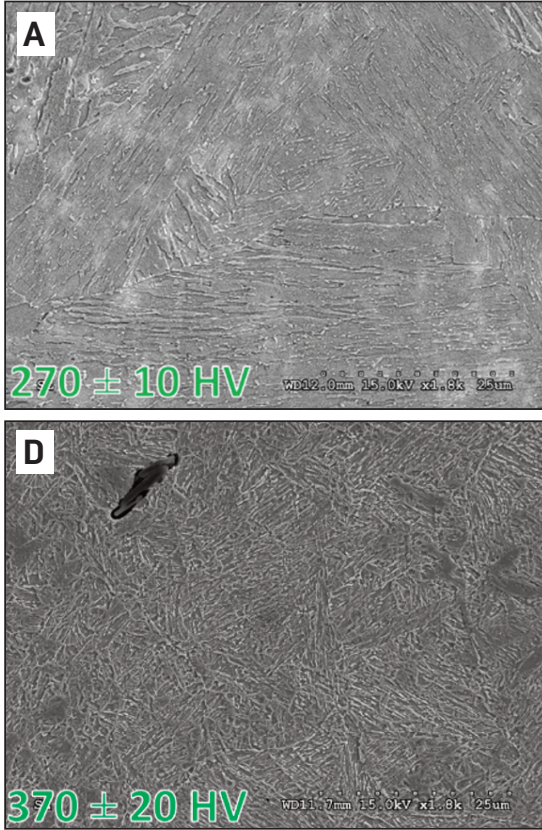
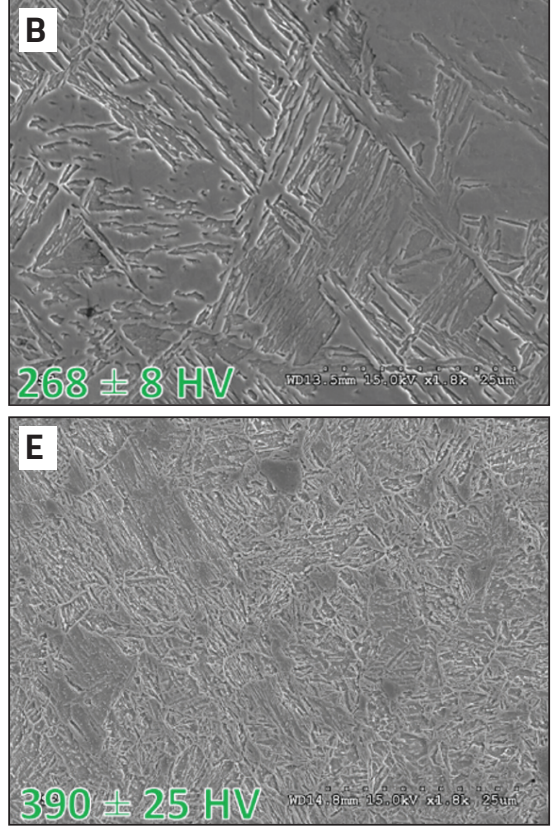
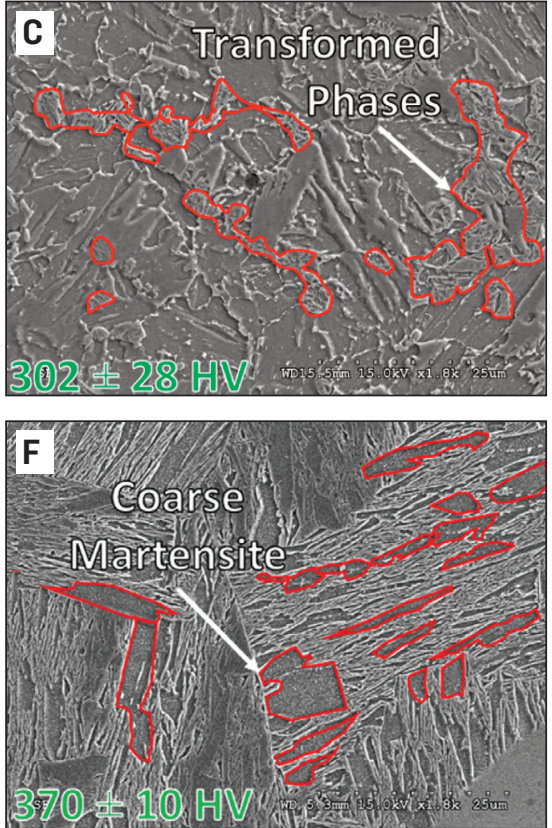

Fig. 9 - SEM of single pass with hardness: A - Base metal; B - SCHAZ; C - ICHAZ; D - HICHAZ; E - FGHAZ; F - CGHAZ.

Considering the single-pass results first, the hardness of the $\mathrm{HAZ}$ remained above the BM value, sharply increasing through the intercritical region and reaching a maximum for the FGHAZ. There was a relatively wide variation in hardness that is attributed to banding. This hardness variation was greatest for the ICHAZ and HICHAZ due to the shift in transformation temperatures for each band. The impact toughness of the HAZ increased from the base metal to the SCHAZ and reached a peak toughness in the HICHAZ. The FGHAZ had lower toughness, but it was still comparable to the BM. The toughness in the CGHAZ was slightly below the accepted minimum for the intended application of the BM, but it did not degrade further when exposed to up to three thermal cycles. The hardness of the CGHAZ also stayed consistent.

The results of the pre-strained (PS) HAZ showed that the toughnesses for the BM and SCHAZ were both lower than the strain-free samples. This was expected because the plastic strain will exhaust some of the ductility of the BM, and the thermal cycle of the SCHAZ was not of sufficient time and temperature to increase the ductility significantly via recovery and recrystallization. Application of plastic strain reduced the toughness in the ICHAZ and HICHAZ relative to the strain-free specimens. Both of these regions showed an increase in toughness relative to the BM and SCHAZ regions, albeit a smaller increase than for the single-pass sample. The FG and CGHAZ both had toughness values close to the single-pass samples, as the temperature was high enough to induce recovery, recrystallization (for the FG-
HAZ), and grain growth (for the CGHAZ) (Ref. 33). The hardness of the BM was only slightly higher for the PS as compared to the strain-free sample. This was expected since HSLA-100 has low work hardening (Ref. 34-36). The hardness of the PS samples in the HAZ above the $\mathrm{Ac}_{3}$ temperature are generally slightly softer than the strain-free samples.

In the intercritical region, the hardness increased after each thermal cycle, and the impact toughness remained below that of the first pass. This trend was not picked up by the HAZ hardness histogram for the autogenous weld passes, as the change in hardness was comparable in scale to the scatter as a result of banding. Additionally, it was clear here that the peak hardness of the ICHAZ as well as the HICHAZ, FGHAZ, and CGHAZ all had similar hardness. An increase in hardness in the ICHAZ masked the hardness of the higher peak temperature HAZ sections. HAZ simulations allow for the hardness of each HAZ to be analyzed separately from each other, resulting in clearer trends. Although there is a decrease in impact toughness, it is still above the required minimum for the base metal. In both cases, the impact toughness was comparable to the base metal, but it was still lower than the peak toughness after the first pass.

To analyze these changes, dilatometry was performed on a sample that was held at the ICHAZ and HICHAZ peak temperature - Fig. 7. These dilatometry tests were identical to the ICHAZ and HICHAZ thermal cycles, except that at the peak temperature the temperature remained constant for 5

Table 3 - Minute Isothermal Hold Results

\begin{tabular}{ccccc}
$\begin{array}{c}\text { Isothermal Hold } \\
\text { Temperature }\end{array}$ & $\mathrm{t}_{\text {peak }}[\mathrm{s}]$ & $\mathrm{t}_{\text {start }}[\mathrm{s}]$ & $\Delta \mathrm{t}_{\text {transform }}[\mathrm{s}]$ & $\Delta$ Dilation \\
\hline $750^{\circ} \mathrm{C}$ & 10 & 47 & 188.5 & 5.1 \\
$810^{\circ} \mathrm{C}$ & 15.5 & 2 & 40 & 8.4 \\
\hline
\end{tabular}



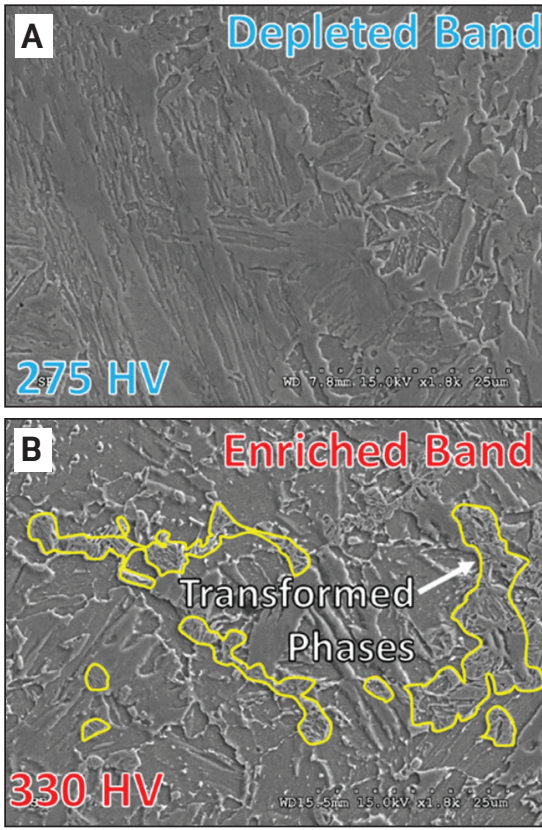
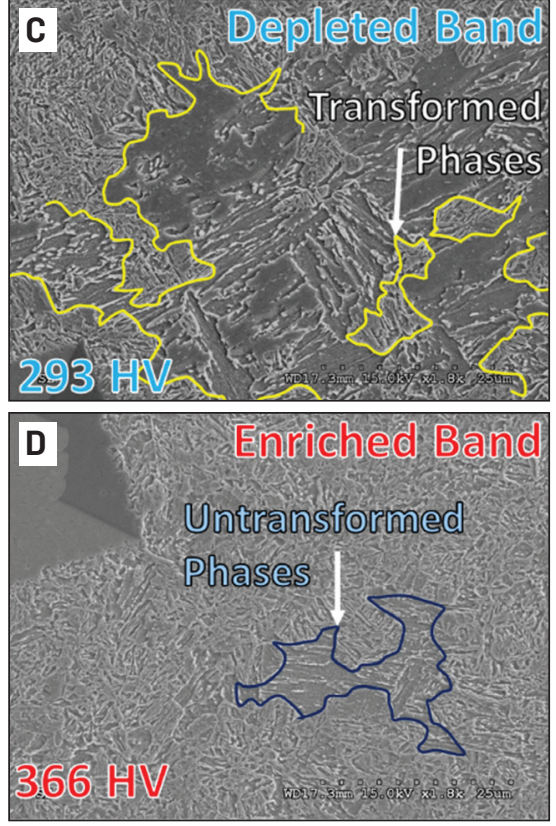
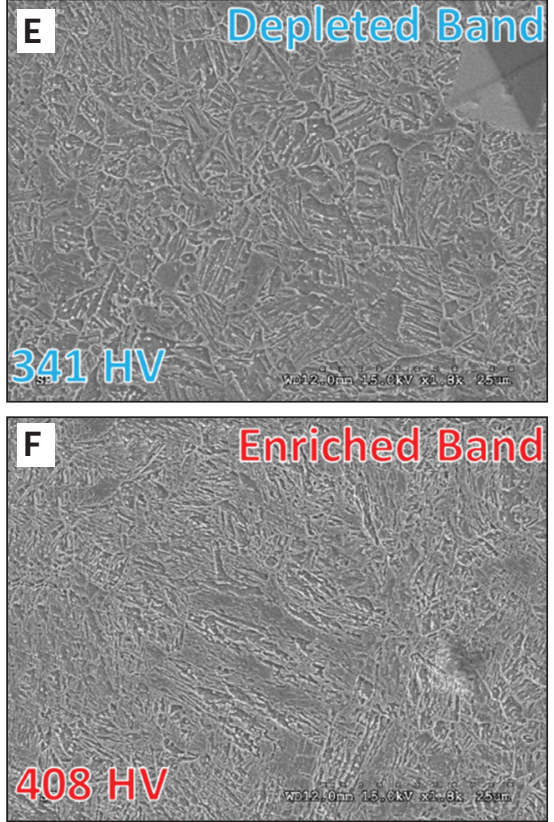

Fig. 10 - SEM with hardness of ICHAZ: A - Single-pass depleted band; B - single-pass enriched band; $C$ - two-pass depleted band; $D$ - two-pass enriched band; $E$ - full-transform depleted band; $F$ - full-transform enriched band.

min. The time it took to cease the transformation was recorded. The ICHAZ took $240 \mathrm{~s}$ from the peak temperature to fully transform, while the HICHAZ took only $45 \mathrm{~s}$ to fully transform (Table 3).

A single weld pass most likely does not remain at the peak temperature long enough to permit full transformation. It is important to note that "full" transformation as used here does not imply that the sample will completely transform into austenite. The austenite transformation will still not be complete since the peak temperature is between the $\mathrm{Ac}_{1}$ and $\mathrm{Ac}_{3}$ temperatures. Thus the "full" transformed state is reached when the thermodynamic equilibrium ratio of ferrite and austenite at that temperature is met. For example, for a heat input of $2150 \mathrm{~J} / \mathrm{mm}$, an ICHAZ thermal cycle remains above the $\mathrm{Ac}_{1}$ temperature for only $1.6 \mathrm{~s}$, well below the $240 \mathrm{~s}$ for a full transformation. However, with successive weld passes, the intercritical regions of the HAZ specimens would get closer and closer to a "fully" transformed state, as is supported by the changes in properties. Thus, the increase in hardness and change in toughness with successive passes observed in Fig. 6 can be attributed to the additional extent of transformation that occurs with each additional pass. However, when these regions of the HAZ are "fully" transformed, there should be no further significant changes in properties (assuming no significant effect from tempering of the fully transformed microstructure).

Fully transformed samples were prepared by heating the sample up to the peak temperature, holding it until it fully transformed (240 or $45 \mathrm{~s}$ depending on the sample), and then cooling it as a typical thermal cycle. These fully transformed samples had higher hardness and lower toughness than the single-pass samples, but the toughness values were still above that of the BM.

For weld repairs and multipass welding, low-alloy steels may experience the LBZ phenomena. The LBZ usually contains blocky martensite-austenite constituent (M-A con- stituent) phases, which can significantly reduce toughness due to phase debonding and crack formation (Refs. 13, 3741). The LBZ has been found in low-alloy steels to occur primarily in the intercritically reheated CGHAZ (ICR CGHAZ) or the CGR CGHAZ (Refs. 13, 39) where a sample underwent a CGHAZ thermal cycle, followed by a reheat thermal cycle to the ICHAZ or CGHAZ, respectively. Thus, HSLA100 CGHAZ samples were reheated to a secondary peak temperature, and the hardness and impact toughnesses of the samples were determined - Fig. 8.

The subcritically reheated CGHAZ (SCR CGHAZ) showed only a small reduction in toughness, and the ICR CGHAZ for HSLA-100 was within scatter of the single-pass CGHAZ. The high intercritically reheated CGHAZ (HICR CGHAZ) and the fine-grained reheated CGHAZ (FGR CGHAZ) both showed a toughness rejuvenation, which increased the toughness to a value above the minimum for the BM. Thus, subsequent reheating of the CGHAZ does not appear to cause a significant decrease in toughness.

\section{Microstructural Evolution}

SEM micrographs of the simulated single-pass samples are shown in Fig. 9. The BM is primarily tempered martensite and acicular ferrite (Ref. 1). Previous TEM studies have shown that HSLA-100 is strengthened by copper precipitates and niobium carbonitrides (Refs. 1, 42-44).

Figure 9A and B shows the BM and SCHAZ both have tempered phases present. Figure $9 \mathrm{C}$ shows the ICHAZ has the same tempered base structure with some small transformed lath-like phases apparent on lath and prior austenite grain boundaries. The increase in hardness between the BM and ICHAZ is associated with this new transformation product (which is likely bainite and/or martensite). Figure 9D and E shows the HICHAZ and FGHAZ, respectively. These 

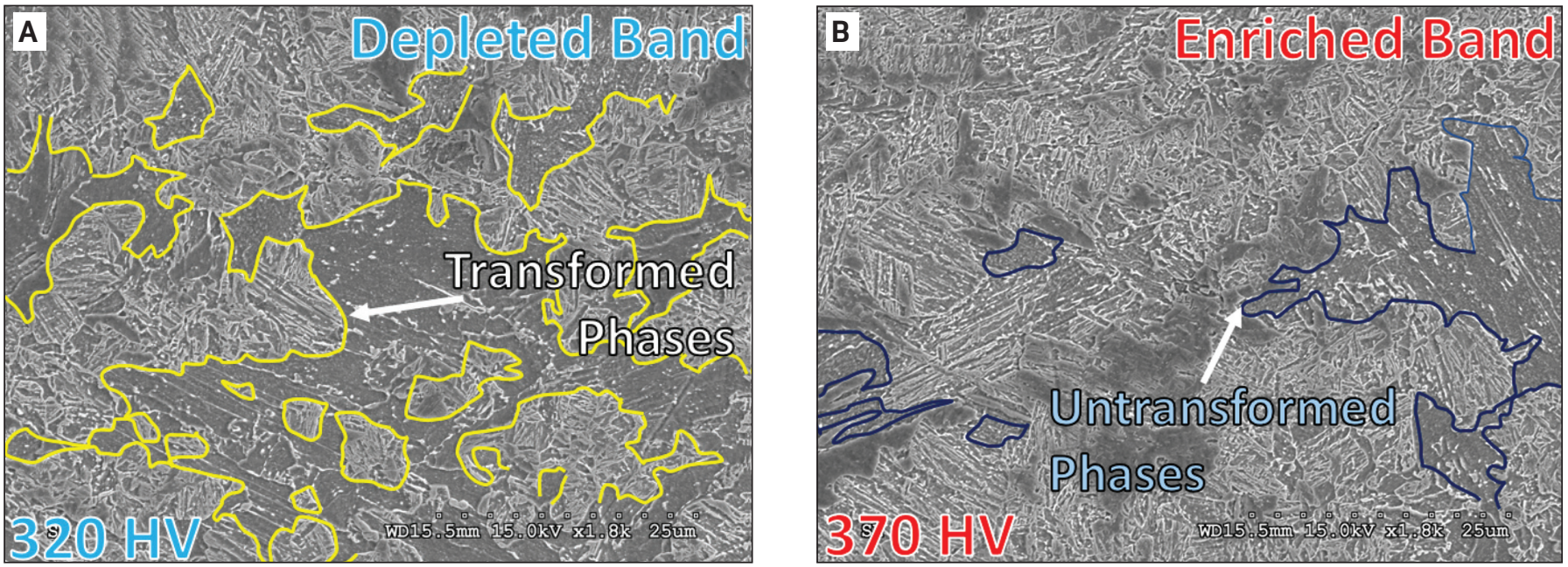

Fig. 11 - Depleted and enriched band of the PS ICHAZ with transformed phases labeled.

Table 4 - Nominal HSLA-100 Simulated Carbide Phase Dissolution Temperature

Thermo-Calc Simulated Phase Dissolution Temperature $\left[{ }^{\circ} \mathrm{C}\right]$

$\begin{array}{cc}\text { Cementite } & 652 \\ \text { M23C6 } & 672 \\ \text { M6C } & 715 \\ \text { Nb }(C, N) & 1120\end{array}$

regions look very similar, with refined grain structure, but the average hardness values are higher for the FGHAZ, indicating full transformation. Figure 9F shows the CGHAZ microstructure. The large prior austenite grains, fresh martensite, and coarse autotempered martensite explain why the CGHAZ has low toughness. Coarse martensite is a well-documented phase that often appears in the CGHAZ of HSLA100 (Refs. 1, 45, 46) and other low-carbon steels (Refs. 4749). It should be mentioned that it is different than plate martensite, which occurs for high-carbon steels. Differences often can only be determined using transmission electron microscopy (TEM), which can identify twin boundaries and midrib features typical of plate martensite but not coarse martensite. However, it is known to significantly lower the toughness (Refs. 49, 50).

The intercritical samples, ICHAZ and HICHAZ, showed the largest change in toughness with multiple weld thermal cycles. Although the SCHAZ and FGHAZ both showed a change in hardness and toughness, the change was relatively small and within scatter of the first pass. The CGHAZ showed no substantial change in hardness or toughness.

Figure 10 shows the ICHAZ as it progresses through the increasing amount of transformation from the single-pass ICHAZ, to the ICR ICHAZ, to the "full" ICHAZ. The transformed regions were identified as the lath structure of the transformed regions was noticeably finer than the tempered martensite matrix. Additionally, the globular shape of the transformed regions for the ICHAZ-enriched band stood out against the larger prior austenite grain boundaries. The hardness in the depleted band of the first pass was on average $275 \mathrm{HV}$, while the hardness of the enriched band was
$330 \mathrm{HV}$. The microstructure of the depleted band was very similar to the tempered martensite of the BM and SCHAZ, with similar hardness to both samples. Any phase transformation in the depleted band was subtle. However, the enriched band showed these transformed phases discussed previously, with an increase in hardness by $55 \mathrm{HV}$. The ICR ICHAZ showed transformed phases in the depleted band that were not visible in the single-pass ICHAZ, as well as a corresponding increase in hardness by almost $20 \mathrm{HV}$. For the enriched band, the small transformed phases appear to have grown to cover almost the entire sample, only leaving a few untransformed regions visible. The hardness of the enriched band increased by $36 \mathrm{HV}$. This progressive phase transformation led to the increase in hardness and change in toughness that were described earlier. The differences between the depleted and enriched band were harder to discern microstructurally in the fully transformed samples, but there was still a significant difference in hardness due to the compositional variations previously described.

The PS samples that underwent HAZ simulations showed lower toughness for the BM and SCHAZ due to nonrecovered cold working. The PS FGHAZ and PS CGHAZ both showed similar hardness and toughness values as their counterpart strain-free samples. The microstructure of the PS samples did not appear significantly different than their single-pass counterparts, except for the ICHAZ. The PS ICHAZ had hardness and toughness values closer to the ICR ICHAZ instead of the ICHAZ. The microstructure of the PS ICHAZ (Fig. 11) showed the same transformed austenite phases seen in the ICHAZ. However, the amount of phase transformation was significantly increased as compared to the single-pass ICHAZ. The depleted band, which did not show any transformed phases for the single-pass ICHAZ, had transformed regions for the PS ICHAZ. The enriched band, which saw limited phase transformation for the ICHAZ, had substantially higher volume fraction of transformed phases for the PS ICHAZ. This trend, limited transformed phases in the depleted band and substantial transformed phases in the enriched band, was similar to the ICR ICHAZ, which has toughness and hardness values within the scatter of the PS ICHAZ. Comparing the enriched and depleted bands of the PS ICHAZ and the unstrained ICHAZ showed there is an apparent increase in transformation when 

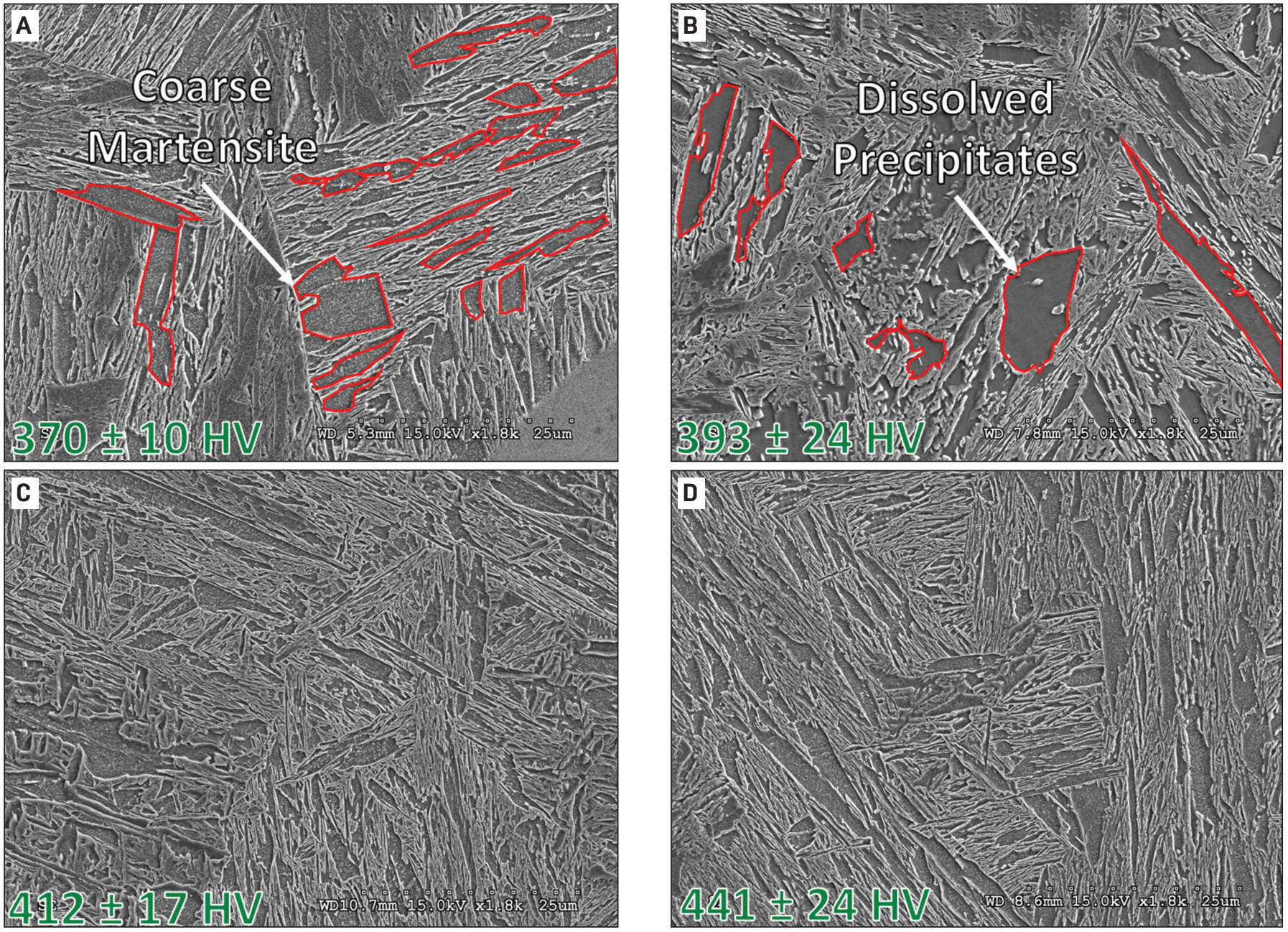

Fig. 12 - SEM of the following: A - CGHAZ; B - ICR CGHAZ; C - HICR CGHAZ; and; D - FGR CGHAZ.

strain is applied. However, this potentially could be due to compositional differences like those seen for the enriched and depleted band. EPMA traces would need to be done to confirm the differences in transformation are due to the large amount of cold working, not compositional differences.

The low toughness of the CGHAZ can be attributed to asquenched martensite, coarse prior austenite grains, and coarse martensite (Ref. 1). The FGHAZ may also likely exhibit as-quenched martensite, so this factor is most likely not as important as the other two. Coarse grains reduce the amount of crack diversion in a given area, reducing the amount of energy absorbed. Coarse martensite is the larger auto-tempered phases that have been shown to reduce toughness (Refs. 49, 50).

The CGHAZ and the ICR CGHAZ both looked very similar, except that for the ICR CGHAZ sample; the cementite particles in the coarse martensite had mostly dissolved Fig. 12A and B. The dissolution of carbides in the ICR CG$\mathrm{HAZ}$ and the increase in hardness was studied in greater detail. Thermo-Calc simulations of the nominal HSLA-100 composition were done to determine the dissolution temperature of different carbides, as shown in Table 4. All carbides present in the simulation, except for the $\mathrm{Nb}(C, N)$, dissolved in the intercritical region. It is well known that $\mathrm{Nb}$
$(C, N)$ help with grain refinement and are stable in the HAZ up until the CGHAZ, where they dissolve (Ref. 1). The simulation estimates the following: cementite dissolves at $652^{\circ} \mathrm{C}$, well below the peak temperature of $750^{\circ} \mathrm{C}$ for the ICHAZ. Although Thermo-Calc simulations assume equilibrium and thus tend to show lower temperatures for phase dissolution or transformation, it can be assumed there was some, if not complete, dissolution at $750^{\circ} \mathrm{C}$.

Thus, the increase in hardness in the ICR CGHAZ was due to two factors. First, there was locally increased carbon content in the coarse martensite grains due to the dissolution of these carbides, as mentioned previously. This increase in carbon content will strengthen the martensitic matrix, similar to what was observed for the enriched band, as compared to the depleted band. Secondly, the increase in composition due to this dissolution of carbides will lead to a decrease in the $\mathrm{Ac}_{1}$ temperature. This was also shown in the enriched band, where the enriched band started transformation before the depleted band. This decrease in the $\mathrm{Ac}_{1}$ temperature will lead to more austenite transformation on heating. This austenite transformation on heating would lead to grain refinement, increasing the toughness. Since there is not a substantial change in toughness of the ICR CGHAZ as compared to the single-pass CGHAZ, there is likely limited 
austenite transformation on heating. This limited transformation is associated with the short time above the $\mathrm{Ac}_{1}$ temperature and the reduction of boundaries the austenite would precipitate on. Therefore, the increase in hardness for the ICR CGHAZ is mostly due to the local carbon enrichment due to dissolved carbides, which would cause the small hardness increase (20 HV) as compared to the CGHAZ.

There is no evidence of $\mathrm{M}-\mathrm{A}$ constituents in any section of the reheated CGHAZ and thus no LBZ phenomena. The HICR CGHAZ and FGR CGHAZ samples both show a great deal more grain refinement, and a reduction in the size of the coarse martensite - Fig. $12 \mathrm{C}$ and D. This grain refinement and coarse martensite reduction is the most likely cause for the increase in toughness. The increase in hardness may be due to grain refinement as well, following the Hall-Petch relationship.

\section{Conclusion}

The influence of multiple thermal cycles in the microstructure and properties of HSLA-100 was investigated with autogenous GTA welds and HAZ simulations. The mechanical property results were complemented by microstructural modeling and characterization. The main results and conclusions are summarized as follows:

1. Thermo-Calc and DICTRA simulations show the soluterich bands have higher carbon content and higher hardenability than the solute-depleted band, and this primarily accounts for the higher hardness in the solute-rich bands.

2. For autogenous welds, local hardness variations due to compositional banding are more significant than the influence of multiple weld thermal cycles.

3. The ICHAZ experiences increasing transformation with each successive pass that generally produces increases in hardness and decreases in toughness. However, the "fully" transformed ICHAZ region still maintained toughness values above that of the BM.

4. The CGHAZ toughness (46 ft-lb) is slightly below the minimum toughness for the base metal ( $60 \mathrm{ft}-\mathrm{lb})$, but application of three CGHAZ thermal cycles did not induce any additional decrease in toughness.

5. Application of $10 \%$ strain prior to the weld thermal cycle reduces the toughness of the BM, SCHAZ, and ICHAZ regions, but the toughness of these regions are still maintained above minimum acceptable levels. The toughness of the FGHAZ and CGHAZ regions exposed to $10 \%$ strain was similar to that of the strain-free samples.

6. The toughness of the CGHAZ is improved when heated to the high temperature intercritical and fine grain HAZ regions due to microstructural refinement.

\section{Acknowledgments}

The authors would like to acknowledge the financial support from the National Science Foundation through the industry/university cooperative research center grant to the Manufacturing and Materials Joining Innovation Center (Ma2JIC). They would also like to thank Matthew Johnson, Daniel Javernick, and David Tung from Los Alamos National Laboratory for their assistance and discussion.

\section{References}

1. Spanos, G., Fonda, R. W., Vandermeer, R. A., and Matuszeski, A. 1995. Microstructural changes in HSLA-100 steel thermally cycled to simulate the heat-affected zone during welding. Metall. Mater. Trans. A 26(12): 3277-3293. DOI: 10.1007/BF02669455

2. Alkhader, M., and Bodelot, L. 2011. Large strain mechanical behavior of HSLA-100 steel over a wide range of strain rates. J. Eng. Mater. Technol. 134: 011005. DOI: 10.1115/1.4005268

3. Park, T. W., and Kang, C. Y. 2000. The effects of PWHT on the toughness of weld HAZ in Cu-containing HSLA-100 steel. ISIJ Int. 40: S49-S53. DOI: 10.2355/isijinternational. 40.Suppl_S49

4. Ricks, R. A., Howell, P. R., and Barritte, G. S. 1982. The nature of acicular ferrite in HSLA steel weld metals. J. Mater. Sci. 17(3): 732-740. DOI: 10.1007/BF00540369

5. Czyryca, E. J., et al. 1990. Development and certification of HSLA-100 steel for naval ship construction. Nav. Eng. J. 102: 6382. DOI: $10.1111 / j .1559-3584.1990 . t b 02632 . x$

6. McNutt, S. A. 1988. Stress relief cracking in copper-precipitation strengthened HSLA-100 steel. Master thesis, Naval Postgraduate School, Monterey, Calif.

7. Arioka, K., Iijima, Y., and Miyamoto, T. 2015. Rapid nickel diffusion in cold-worked carbon steel at $320-450^{\circ} \mathrm{C}$. Philos. Mag. 95: 3577-3589. DOI: 10.1080/14786435.2015. 1091108

8. Love, G. R. 1964. Dislocation pipe diffusion. Acta Metall. 12(6): 731-737. DOI: 10.1016/0001-6160(64)90220-2

9. Huang, J., Meyer, M., and Pontikis, V. 1989. Is pipe diffusion in metals vacancy controlled? A molecular dynamics study of an edge dislocation in copper. Phys. Rev. Lett. 63: 628-631. DOI: 10.1103/PhysRevLett.63.628

10. Singh, R., et al. 2003. The effects of cold working on sensitization and intergranular corrosion behavior of AISI 304 stainless steel. Metall. Mater. Trans. A 34(11): 2441-2447. DOI: 10.1007/s11661003-0004-5

11. Chung-Min, C., and Varma, S. K. 1989. Vacancy versus pipe diffusion mechanisms for subgrain growth in OFHC copper. Acta Metall. 37(3): 927-932. DOI: 10.1016/ 0001-6160(89)90019-9

12. Karimi, Y., Hossein Nedjad, S., Miyamoto, G., Shirazi, H., and Furuhara, T. 2017. Banding effects on the process of grain refinement by cold deformation and recrystallization of acicular C-Mn steel. Mater. Sci. Eng. A 697: 1-7. DOI: 10.1016/j.msea.2017.05.006

13. Kim, B. C., Lee, S., Kim, N. J., and Lee, D. Y. 1991. Microstructure and local brittle zone phenomena in high-strength low-alloy steel welds. Metall. Trans. A 22(1): 139-149. DOI: 10.1007/ BF03350956

14. Kerr, H. W. 1976. A review of factors affecting toughness in welded steels. Int. J. Press. Vessel. Pip. 4(2): 119-141. DOI: 10.1016/ 0308-0161(76)90015-6

15. Hu, J., et al. 2014. High toughness in the intercritically reheated coarse-grained (ICRCG) heat-affected zone (HAZ) of low carbon microalloyed steel. Mater. Sci. Eng. A 590: 323-328. DOI: 10.1016/ j.msea.2013.10.062

16. Lolla, T. 2014. Understanding the role of initial microstructure on intercritically reheated heat affected zone microstructure and properties of multi-pass welds. PhD disseration, The Ohio State University, Materials Park, Ohio.

17. Li, X., Fan, Y., Ma, X., Subramanian, S. V., and Shang, C. 2015. Influence of martensite-austenite constituents formed at different intercritical temperatures on toughness. Mater. Des. 67: 457-463. DOI: 10.1016/j.matdes.2014.10. 028

18. Luo, X., Chen, X., Wang, T., Pan, S., and Wang, Z. 2018. Effect of morphologies of martensite-austenite constituents on impact toughness in intercritically reheated coarse-grained heat-affected zone of HSLA steel. Mater. Sci. Eng. A 710: 192-199. DOI: 10.1016/j.msea.2017.10.079

19. Bonnevie, E., Ferriere, G., Ikhlef, A., Kaplan, D., and Orain, J. M. 2004. Morphological aspects of martensite-austenite constituents 
in intercritical and coarse grain heat affected zones of structural steels. Mater. Sci. Eng. A 385(1-2): 352-358. DOI:

10.1016/j.msea.2004.06.033

20. Zhu, Z., Kuzmikova, L., Li, H., and Barbaro, F. 2014. Effect of inter-critically reheating temperature on microstructure and properties of simulated inter-critically

reheated coarse grained heat affected zone in X70 steel. Mater. Sci. Eng. A 605: 8-13. 10.1016/j.msea.2014.03.034

21. Fuerschbach, P. W. 2008. Control of photonic package alignment with asynchronous laser spot welds. IEEE Trans. Electron. Packag. Manuf. 31(2): 114-119. DOI: 10.1109/ TEPM.2008.919328

22. Fuerschbach, P. W., Eisler, G. R., and Steele, J. R. Weld procedure development with OSLW - optimization software for laser welding, pp. 1-4. Sandia National Laboratories, Albuquerque, N. Mex.

23. Fuerschbach, P., Norris, J., Dykhuizen, R., and Mahoney, A. 2004. Development and evaluation of an in-situ beam measurement for spot welding lasers. Welding Journal 83(5): 154-s to 159-s.

24. Andersson, J. O., Helander, T., Höglund, L., Shi, P., and Sundman, B. 2002. Thermo-Calc \& DICTRA, computational tools for materials science. Calphad Comput. Coupling Phase Diagrams Thermochem. 26(2): 273-312. 10.1016/ S0364-5916(02)00037-8

25. Borgenstam, A., Höglund, L., Ågren, J., and Engström, A. 2000. DICTRA, a tool for simulation of diffusional transformations in alloys. J. Phase Equilibria 21: 269-280. DOI: 10.1361/ 105497100770340057

26. Powell, R., Holland, T., and Worley, B. 1998. Calculating phase diagrams involving solid solutions via non-linear equations, with examples using THERMOCALC. J. Metamorph. Geol. 16(4): 577-588. DOI: 10.1111/j.1525-1314.1998.00157.x

27. Sundman, B., Jansson, B., and Andersson, J. O. 1985. The Thermo-Calc databank system. Calphad 9(2): 153-190. DOI: 10.1016/0364-5916(85)90021-5

28. Sundman, B., and Ågren, J. 1980. A regular solution model for phases with several components and sublattices, suitable for computer applications. Trita-Mac 166: 17.

29. Majka, T. F., Matlock, D. K., and Krauss, G. 2002. Development of microstructural banding in low-alloy steel with simulated Mn segregation. Metall. Mater. Trans. A 33(6): 1627-1637. DOI: 10.1007/s11661-002-0172-8

30. Lavender, J. D., and Jones, F. W. 1949. An investigation on banding. J. Iron Steel Inst. 163: 14-17.

31. Grange, R. A., Hribal, C. R., and Porter, L. F. 1977. Hardness of tempered martensite in carbon and low-alloy steels. Met. Trans. A 8(11): 1775-1785. DOI: $10.1007 /$ BF02646882

32. de la Concepción, V. L., Lorusso, H. N., and Svoboda, H. G. 2015. Effect of carbon content on microstructure and mechanical properties of dual phase steels. Procedia Mater. Sci. 8: 1047-1056. DOI: 10.1016/j.mspro.2015.04.167

33. Kou, S. 2003. Welding Metallurgy. John Wiley \& Sons Inc.

34. Dhua, S. K., Mukerjee, D., and Sarma, D. S. 2001. Influence of tempering on the microstructure and mechanical properties of HSLA-100 steel plates. Metall. Mater. Trans. A 32(9): 2259-2270. DOI: $10.1007 / s 11661-001-0201-z$

35. Ray, P. K., Ganguly, R. I., and Panda, A. K. 2003. Optimization of mechanical properties of an HSLA-100 steel through control of heat treatment variables. Mater. Sci. Eng. A 346(1-2): 122-131. DOI: 10.1016/S0921-5093(02)00526-9

36. Alkhader, M., and Bodelot, L. 2012. Large strain mechanical behavior of HSLA-100 steel over a wide range of strain rates. J. Eng. Mater. Technol. 134(1): 011005. DOI: 10.1115/1.4005268
37. Li, X., Ma, X., Subramanian, S. V., Shang, C., and Misra, R. D. K. 2014. Influence of prior austenite grain size on martensite-austenite constituent and toughness in the heat affected zone of $700 \mathrm{MPa}$ high strength linepipe steel. Mater. Sci. Eng. A 616: 141-147. DOI: 10.1016/j.msea.2014.07.100

38. Lambert, A., Drillet, J., Gourgues, A. F., Sturel, T., and Pineau, A. 2000. Microstructure of martensite-austenite constituents in heat affected zones of high strength low alloy steel welds in relation to toughness properties. Sci. Technol. Weld. Join. 5(3): 168-173. DOI 10.1179/ 136217100101538164

39. Mohseni, P., Solberg, J. K., Karlsen, M., Akselsen, O. M., and Østby, E. 2014. Cleavage fracture initiation at M-A constituents in intercritically coarse-grained heat-affected zone of a HSLA steel. Metall. Mater. Trans. A 45(1): 384-394. DOI: 10.1007/s11661-013-2110-3

40. Lan, L., Qiu, C., Zhao, D., Gao, X., and Du, L. 2012. Analysis of martensite-austenite constituent and its effect on toughness in submerged arc welded joint of low carbon bainitic steel. J. Mater. Sci. 47(11): 4732-4742. DOI: $10.1007 /$ s10853-012-6346-x

41. Thompson, S. W. 2018. Interrelationships between yield strength, low-temperature impact toughness, and microstructure in low-carbon, copper-precipitation-strengthened, high-strength low-alloy plate steels. Mater. Sci. Eng. A 711: 424-433. DOI:

10.1016/j.msea.2017.11.022

42. Mishra, S. K., Das, S., and Ranganathan, S. 2002. Precipitation in high strength low alloy (HSLA) steel: A TEM study. Mater. Sci. Eng. A 323(1-2): 285-292. DOI: 10.1016/ S0921-5093(01)01382-X

43. Wang, H. H., Tong, Z., Hou, T. P., Wu, K. M., and Mehmood, T. 2016. Effects of evolution of nanoscale copper precipitation and copper content on mechanical properties of high-strength steel weld metal. Sci. Technol. Weld. Join. 22(3): 191-197. DOI:

10.1080/13621718.2016.1213583

44. Bhagat, A. N., Pabi, S. K., Ranganathan, S., and Mohanty, O. N. 2004. Aging behaviour in copper bearing high strength low alloy Steels. ISIJ Int. 44(1): 115-122. DOI: 10.2355/ isijinternational. 44.115

45. Rowenhorst, D. J., Gupta, A., Feng, C. R., and Spanos, G. 2006 3D crystallographic and morphological analysis of coarse martensite: Combining EBSD and serial sectioning. Scr. Mater. 55(1): 11-16. DOI 10.1016/j.scriptamat.2005. 12.061

46. Fonda, R. W., Spanos, G., and Vandermeer, R. A. 1994. Observations of plate martensite in a low carbon steel. Scripta Metall. et Mat. 31(6): 683-688.

47. Keehan, E., Karlsson, L., Bhadeshia, H. K. D. H., and Thuvander, M. 2008. Three-dimensional analysis of coalesced bainite using focused ion beam tomography. Mater. Charact. 59(7): 877-882. DOI: 10.1016/j.matchar.2007.07. 011

48. Barrick, E. J., Jain, D., DuPont, J. N., and Seidman, D. N. 2017. Effects of heating and cooling rates on phase transformations in 10 wt pct Ni steel and their application to gas tungsten arc welding. Metall. Mater. Trans. A 48(12): 5890-5910. DOI: 10.1007/s11661-0174379-0

49. Pous-Romero, H., and Bhadeshia, H. 2014. Coalesced martensite in pressure vessel steels. J. Press. Vessel Technol. 136(3): 031402. DOI: $10.1115 / 1.4026192$

50. Bhadeshia, H. K. D. H., Keehan, E., Karlsson, L., Andr, H. O., and Andrén, H. 2006. Coalesced bainite. Trans. Indian Inst. Met. 59: 689-694.

JONAH E. DUCH and JOHN N. DUPONT are with Lehigh University, Bethlehem, $\mathrm{Pa}$. 